\title{
Analysis of Vibration Energy Harvesting from Power Consuming Devices
}

\author{
Vahid Jamadar ${ }^{1}$, Pawan Pingle ${ }^{2}$ \\ Research Scholar, Mechanical Engineering Department, BVDU College of Engineering, Pune, India ${ }^{1}$ \\ Professor, Mechanical Engineering Department, BVDU College of Engineering, Pune, India ${ }^{2}$
}

\begin{abstract}
Vibration energy harvesting is one of the most promising technologies. The majority of current researchers obtain $10 \mathrm{~mW}$ to $100 \mathrm{~mW}$ power, [2] which has only limited applications in self-powered wireless sensors and lowpower electronics. The vibrations in some situations can be very large, for example, the vibrations of tall Buildings , long bridges, vehicle systems, railroads, ocean waves, and even human motions.
\end{abstract}

Keywords: machines vibration, VEH, piezo-electric, vibration energy.

\section{INTRODUCTION}

Simply stated, vibration energy harvesting is the process by which otherwise wasted vibration is harvested and converted to useful electrical energy to perpetually power Wireless Sensor Nodes (WSN).[5]

Energy harvesting is defined as capturing minute amounts of energy from one or more of the surrounding energy sources, accumulating them and storing them for later use.[7] Energy harvesting is also called as power harvesting or energy scavenging. With recent advances on wireless and MEMS technology, energy harvesting is highlighted as the alternatives of the conventional battery. Ultra low power portable electronics and wireless sensors use the conventional batteries as their power sources, but the life of the battery is limited and very short compared to the working life of the devices. The replacement or recharging of the battery is inefficient and sometimes impossible. Therefore, a great amount of researchers have been conducting about the energy harvesting technology as a self-power source of portable devices or wireless sensor network system.

\section{ACTUAL WORK, EXPERIMENTATION AND} ANALYSIS

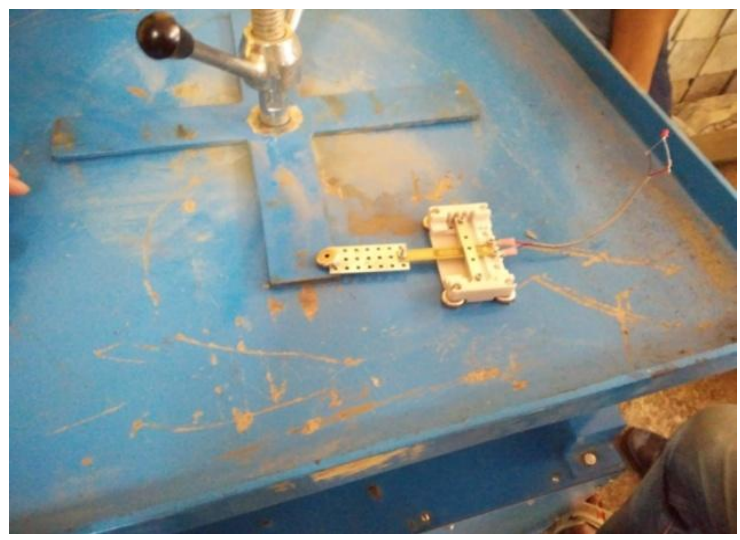

Fig. 1. Vibration Analysis Of Sieve Shaker
I. Frequency analysis.

II. Selection of range and equipment for further work.

III. Selection of VEH.

IV.Assembly and clamping.

V. Mounting.

VI.Observations and readings.

\section{SENSING}

Piezos provide an electrical output when strained and therefore they are often used as sensors. Midé's PPA products size results in a very large output for a given mechanical input. This results in the ability to use piezos as unpowered sensors. This is very useful for applications that require a very long lifetime or where batteries may not be an option. Graph 1 provides a plot comparing the sensitivity of each product to the upper limit of the usable frequency range. This frequency range is defined as when the deviation is within $\pm 3 \mathrm{~dB}$ of the sensitivity.[4] Adding tip mass will increase the sensitivity but it will also greatly reduce the bandwidth of the sensor.

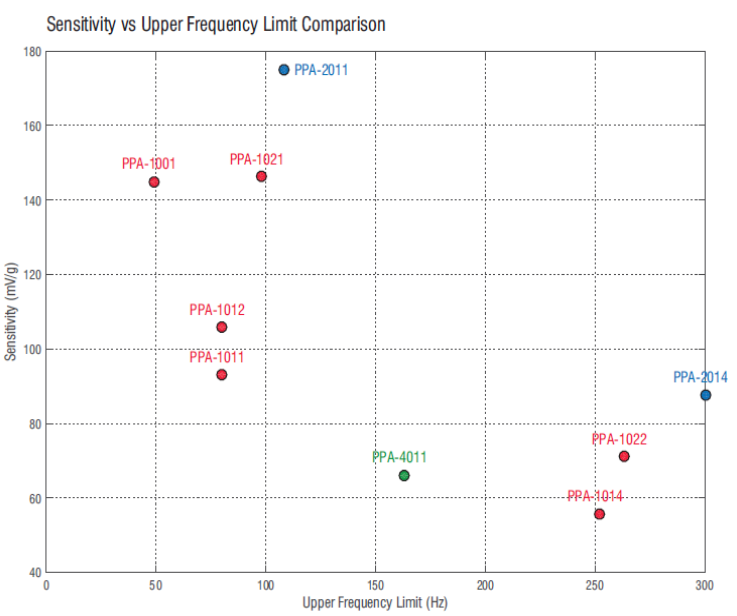

Graph. 1. Sensing Of Different Piezo's. 
IARJSET

These tests were with the piezo clamped in the middle a magnetic field. Thus, through the use of the clamp location. The - 6mm clamp location wouldn't be piezoelectric, the mechanical energy in the system is very useful in this application because it will reduce the passively dampened. bandwidth and the sensitivity because it is not clamped on the piezo. Clamping at the $+6 \mathrm{~mm}$ location will increase the bandwidth but decrease the sensitivity; this may be useful for some applications.[6]

\section{IV.CLAMP LOCATION}

These PPA products[8] were designed for three clamp locations. These clamp lines are detailed on the drawing for each product and shown below with the PPA-9001 clamping kit. The middle clamp location (Clamp 0) is the default position for all products. With this clamp line 5.3 $\mathrm{mm}(0.21 \mathrm{in})$ of the piezo wafer is clamped. This ensures adequate strain in the piezo during energy harvesting and sensing. It also provides a secure moment for delivering high force output in actuation.

Clamp 6 extends $6 \mathrm{~mm}$ toward the tip of the piezo pack. This clamp location is useful when trying to increase the resonant frequency of the beam. Clamp -6 extends $6 \mathrm{~mm}$ away from the tip of the piezo beam. With this clamp configuration the piezo wafer is not directly clamped.

This is ideal for applications where displacement performance is paramount. Not clamping on the piezo makes the pack much less stiff, and thus drives down the resonant frequency. Due to the decreased strain delivered to the piezo it also lengthens the lifetime of the pack. This clamp location is not recommended for energy harvesting, sensing, or force delivery applications due to the lack of strain.

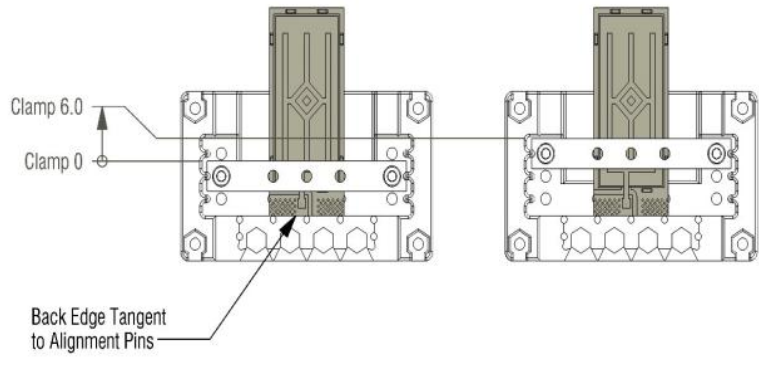

Fig. 2. The PPA-1001 only utilizes the Clamp 0 and Clamp 6 locations.

\section{VIBRATION DAMPING}

Midé's vibration energy harvesters convert mechanical energy into electrical energy. Because of this piezoelectric effect, Midé's piezo products are taking mechanical energy out of the system and providing electrical power to a sensing system.

Thus Midé's energy harvesters can not only harvest otherwise unused energy, it can also prolong the life of the mechanical system the energy is harvested from by dampening vibrations. If vibration dampening is all that is desired from the piezo, a shunt circuit can be utilized to dissipate the harvested mechanical energy into heat and/ or

\section{ACTUAL MOUNTING OF VEH ON SIEVE SHAKER}

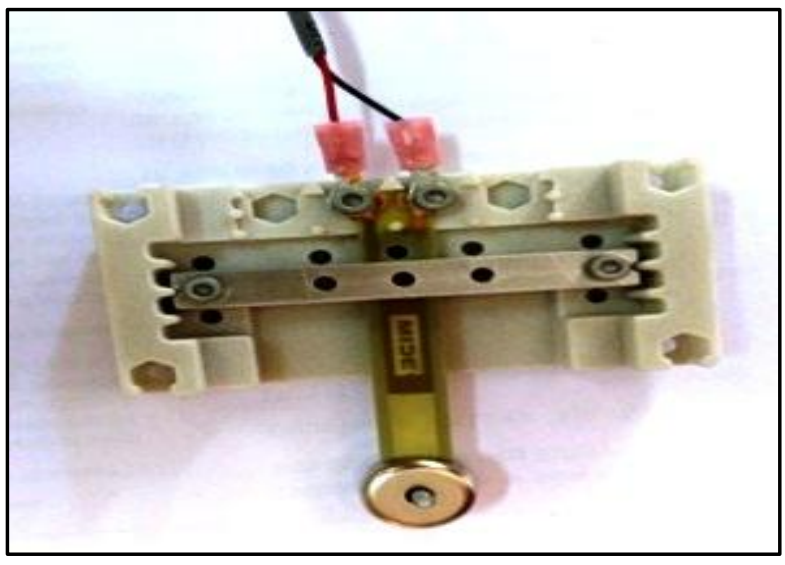

Fig. 3. Vibration Energy Harvester

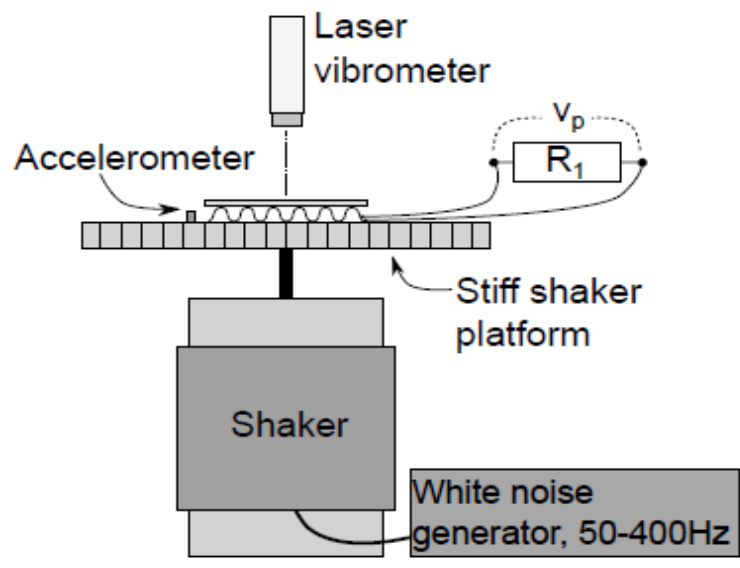

Fig. 4. VEH mounting on sieve shaker.

A. It is identified the machine asset-"Sieve Shaker" to be monitored or used as the vibration source for the Vibration Energy Harvester (VEH).Mounted the VEH at the suggested locations on the machine using the supplied magnetic mounting hardware. It is observed the current output of the VEH with a multimeter (using the supplied cable). If the current reads (in this example) $0.5 \mathrm{~mA}$ or greater the VEH will harvest enough power at that location to produce power. If the current output is less than required (in this case, less than $0.5 \mathrm{~mA}$ ) - move to the next location and repeat step 3 until a proper location is determined.

We attached the VEH using magnets as adherer. Selected the optimized location for the mounting and harvesting enough power. Attached the LED to check the output. After obtaining a stable output of power, the readings were recorded using multimeter. Resister was attached across the circuit to obtain the output in current. Different 
IARJSET

clamping positions were done using Trial and Error method, maximum possible output were found and recorded.

\section{BENEFITS OF VIBRATION ENERGY HARVESTING}

It has long lasting operability and no chemical disposal, it is cost saving too. It is safe with no maintenance. With no charging points with remote accessibility. It is flexible with applications otherwise impossible. It provides sufficient power as when needed. It has adequate lifetime. Easy low cost installation with hassle free operation. Meet application specification requirements no external voltage source. It high voltage $2-10 \mathrm{v}$. It has compact configuration. High coupling in single crystals. They require very less maintenance. It is very cost efficient.

\section{MAIN TECHNICAL LIMITS OF VEH}

Present limits of resonant systems:

Narrow bandwidth that implies constrained resonant frequency-tuned applications. Small inertial mass and maximum displacement at MEMS scale. Low output voltage $(\sim 0,1 \mathrm{~V})$ for electromagnetic systems. Limited power density at micro scale (especially for electrostatic converters), not suitable for mill watt electronics (10$100 \mathrm{~mW})$. Versatility and adaptation to variable vibration sources. Miniaturization issues (micro magnets, piezo beam). Depolarization. Brittleness in PZT. Poor coupling in piezo-film (pvdf). High output impedance.

\section{AREA OF APPLICATION}

Vibrations could be large in many situations. If the energy in large-scale vibration can be successfully harvested, it can serve as either an on-site generator or a power source to feed the grid. Some of the areas of applications of VEH are in following feilds: automotive \& aerospace, military, civil structures, consumer electronics, medical implants, machine shop.[1][3]

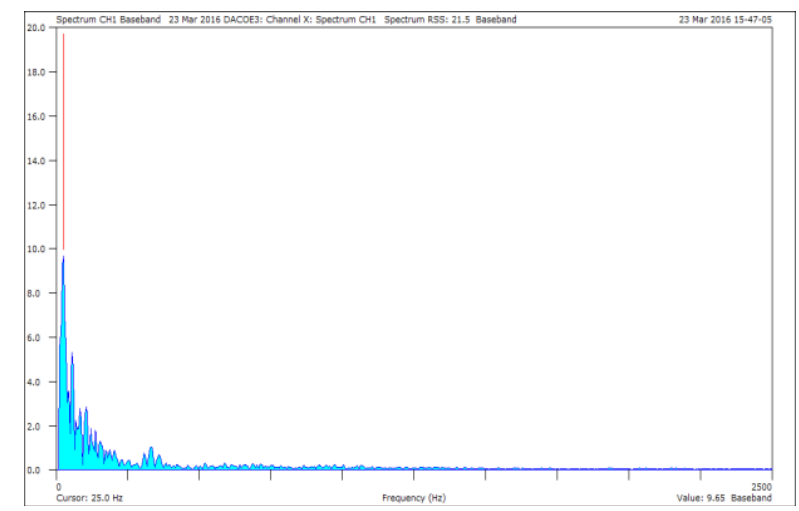

Graph. 2. obtained from sieve shaker.

Database; $Y$ axis $=9.65 \mathrm{db}$

Frequency; $\mathrm{X}$ axis $=25 \mathrm{~Hz}$

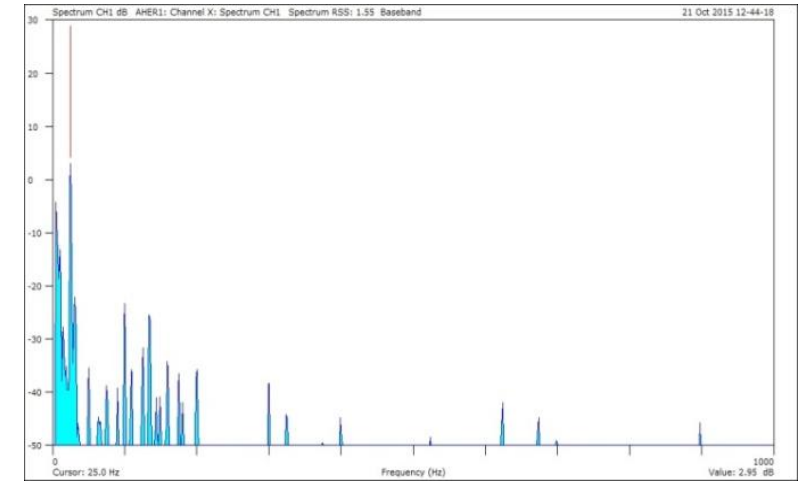

Graph. 3. obtained from motor winding casing.

Database; $Y$ axis $=2.95 \mathrm{db}$

Frequency; $\mathrm{X}$ axis $=25 \mathrm{~Hz}$

For Sieve Shaker:

Maximum Voltage obtained in multimeter across the 100 ohm resister $=2.8$ Volt

So, the current will be calculated by using Ohm's law.

Ohm's law is defined as , $\mathrm{V}=\mathrm{IR}$

Where,

$\mathrm{V}=$ voltage across resister

$\mathrm{R}=$ Resister $(100 \mathrm{ohm})$

$\mathrm{I}=$ Current $(\mathrm{V} / \mathrm{R})$

Sample Calculation:

$\mathrm{I}=\mathrm{V} / \mathrm{R} \quad=2.8 / 100$

$\mathrm{I}=0.028 \mathrm{~A}=28 \mathrm{~mA}$

Similarly, for motor;

$\mathrm{V}=0.085 \mathrm{~V}$

$\mathrm{R}=100 \mathrm{Ohm}$

Therefore,

$\mathrm{I}=\mathrm{V} / \mathrm{R}=0.085 / 100$

$\mathrm{I}=0.00085=0.85 \mathrm{~mA}$

Table. 1. Result Table.

\begin{tabular}{|l|l|l|}
\hline APPLICATION & $\begin{array}{l}\text { TYPE OF } \\
\text { VEH }\end{array}$ & $\begin{array}{l}\text { POWER/ } \\
\text { ENERGY } \\
\text { HARVESTED }\end{array}$ \\
\hline $\begin{array}{l}\text { SIEVE } \\
\text { SHAKER }\end{array}$ & $\begin{array}{l}\text { PIEZO } \\
\text { ELECTRIC }\end{array}$ & $0.0784 \mathrm{~W}, 28 \mathrm{~mA}$ \\
\hline MOTOR & $\begin{array}{l}\text { PIEZO } \\
\text { ELECTRIC }\end{array}$ & $0.07225 \mathrm{~W}, 0.85 \mathrm{~mA}$ \\
\hline
\end{tabular}

\section{RESULT AND CONCLUSION}

It is observed the vibration energy harvesting from "Various machines". In various machines the energy harvested with the help of VEH because VEH absorbs the vibration generated in various machines. The power generated from various machines is very moderate which is up to 30 volt.

In various machines the energy harvested with the help of piezo electric material. The energy generated by this is useful for small applications such as for LED (Light Emitting Diode) which requires only 0.5-1 watt power. 
In motor \& sieve shaker harvested with the help of vibration energy harvester, multimeter, piezoelectric material. The piezoelectric material is mounted on the motor $\&$ sieve shaker so that the power is generated.

\section{ACKNOWLEDGMENT}

The authors would like to express sincere gratitude to Bharati Vidyapeeth Deemed University, College of Engineering, Pune, India and AGTI's Dr. Daulatrao Aher College of Engineering, Karad, Satara, India for their help and support.

\section{REFERENCES}

[1] Vahid Jamadar, Dr. Pawan Pingle and Sandip Kanase, "Possibility of Harvesting Vibration Energy from Power Producing Devices", International Conference on Automatic Control and Dynamic Optimization Techniques (ICACDOT), pp. 1-6, 2016.

[2] Lei Zuo and Xiudong Tang, "Large-scale vibration energy harvesting", Journal of Intelligent Material Systems and Structures, pp. 1405-1430, 2013.

[3] Arifur Rahman and Md.Emdadul Hoque, "Energy generation by using vibration of diesel engine", 2010.

[4] Davide Alghisi, Simona Dalola, Marco Ferrari and Vittorio Ferrari, "Multi-degree of freedom energy harvesting", 2011.

[5] Sujesha Sudevalayam and Purushottam Kulkarni, "Energy Harvesting Sensor Nodes: Survey and Implications", 2008.

[6] G. Park, C. R. Farrar, M. D. Todd, W. Hodgkiss and T. Rosing, "Energy Harvesting for Structural Health Monitoring Sensor Networks", Technical Report, Los Alamos National Laboratories, LA, 2007.

[7] Sravanthi Chalasani and James M. Conrad, "A Survey of Energy Harvesting Sources for Embedded Systems", In: Proceedings of IEEE Southeastcon, Huntsville, Alabama, pp. 442-447, 2008.

[8] MIDE, "ppa-piezo-product-datasheet", 2016.

[9] Francesco Cottone, "Cottone Introduction to vibration harvesting", 2011. 